\title{
E-business Maturity and Information Technology in Portuguese SMEs
}

\author{
Ramiro Moreira Gonçalves ${ }^{1}$, Sónia Sousa Santos ${ }^{1}$ and Elisabete Paulo Morais ${ }^{2}$ \\ ${ }^{1}$ University of Trás-os-Montes and Alto Douro, Vila Real, Portugal \\ ${ }^{2}$ Polytechnic Institute of Bragança, Bragança, Portugal
}

\begin{abstract}
The latest technological advances made over recent times led to a profound market change, characterized by increased competition. In order to be competitive, organizations have been forced to adapt themselves to this new reality, seeking innovative solutions permitting them to achieve lower costs, greater productivity and differentiation from competition.

This work focuses the e-business maturity stages of Portuguese small and medium enterprises (SMEs). Our goal is to identify in which e-business maturity stage they are and explore the relationship between their e-business maturity and the technology they use.
\end{abstract}

Keywords: E-business Maturity, Information Technology, SMEs

\section{Introduction}

With an increasingly global world and a higher degree of competitiveness, organizations who want to survive the challenges of the market, must be able to adapt themselves quickly to fast changing environments. Alves (2009) mentioned that the rising demand for a better service, quality and variety of products, associated to a growing competition, has forced organizations to rethink how to manage their business. This leads to the need for systems that can adapt at the same pace. The information technologies (IT) offer several tools that aim to organize and structure all the processes of an organization, in order to manage the business and gain improved performance in the market. As a result, organizations have adopted several tools of IT a while ago. The spread of the Internet in recent years, in different branches of business, lead most organizations to invest in this medium, which became one of the main channels of communication in organizations. The e-business had much importance in the global economy. Considering the insertion of an organization into e-business is not merely an option but a matter of survival. In a research study by Gonçalves (2005), this is because of the e-business initiatives which, when properly conducted, offer organizations a greater visibility and expansion in their target markets and attract and retain customers through new and innovative ways. This article aims to identify the evolution of the e-business maturity of 500 Portuguese SMEs since 2005 until 2008 and explore the

Copyright (C) 2010 Ramiro Moreira Gonçalves, Sónia Sousa Santos, Elisabete Paulo Morais. This is an open access article distributed under the Creative Commons Attribution License unported 3.0, which permits unrestricted use, distribution, and reproduction in any medium, provided that original work is properly cited. Author contact: Ramiro Moreira Gonçalves, e-mail: ramiro@utad.pt 
relationship between e-business maturity and the technology they use.

\section{E-business}

The term e-business was first used by IBM in 1997 in a campaign on the Internet and IT for conducting business in an organization. This led to the emergence of the e-business concept. IBM defined ebusiness as a safe, flexible and integrated way of providing differentiated value to business through a combination of systems and processes. IBM (1997) mentioned that this combination allows basic business operations in a simple mode and is accessible by using the Internet technology. The e-business concept goes further and encompasses all activities of an organization through the integration of various organizational activities with the Information Systems (IS) and the Internet. The e-business is the integration of people, processes and technology in order to perform business. In sum, Plessis and Boon (2004) mentioned that the e-business is the realization of business by electronic means with the Internet as a communication channel.

\section{Maturity Models}

Even before the emergence of the Internet and the e-business, maturity models were studied by researchers such as Earl (1983) (1989), Gibson et al. (1974), Hirschheim et al. (1988), Galliers and Sutherland (1994), Nolan (1973) and Bhabuta (1988).

Prananto, McKay and Marshall (2004) mentioned that there have been numerous attempts to develop models of maturity since the emergence and growing importance of IT in organizations.

Prananto, McKay and Marshall (2001) considered Nolan to be the first researcher who provided a model to explain the evolution of IS in organizations. This, because Nolan (1973) proposed a model for IS in 1973 which is nowadays one of the best known maturity models.

More recently, with the emergence of the Internet and e-commerce, new models were developed which are better adapted to the reality of the e-business. Several stages of growth models were formulated by KPMG (1997), Grant (1999), Earl (2000), McKay, Prananto and Marshall (2000), Rayport and Jaworsky (2002), Prananto, McKay and Marshall (2001), Rao, Mets and Monge (2003) and Chan and Swatman (2004). These models describe the various phases involved in moving towards greater sophistication with the respect to the use and management of Information Systems/Information Technology in the new e-commerce environment.

Prananto, McKay and Marshall (2003) mentioned that these models aims to capture and describe the various stages involved in the use and management of IT/IS in the new e-business environment by showing the progression of e-business maturity. Thus, organizations are able to determine the level of maturity they achieved by comparing their current situation with the stages of maturity described in the model.

\section{Research Design}

To identify the e-business maturity stage of Portuguese SMEs (during the years 2005 to 2008) and to explore the constraints associated to each maturity stage, there was conducted a study which involved an online questionnaire and a sample of 500 SMEs among the best 1000 Portuguese SMEs in 2007, according to the list published in the Exame (2008) magazine. We obtained 52 valid responses, which corresponds to a $10.8 \%$ response rate, since there has been a return of six letters and fifteen emails who were not delivered due to the correspondence. Since Alreck and Settle (1985), Barnett (1991) and Morais, Pires and Gonçalves (2008) mentioned that the average for this type of questionnaire is between $5-10 \%$, our response rate can be considered as satisfactory. The questionnaire was structured by thematic groups of questions in order to identify the profile of the questionnaire respondents, to characterize the type of organization, to locate each organization at a certain stage of maturity and to analyze the progress during the last years (2005-2008). Therefore, in order to explain the progression of e-business in the context of the Portuguese SMEs, we used 
the SOG-e model.Prananto, McKay and Marshall (2003) defend that as with all other stages of growth models, the SOG-e model assumes that a normal progression is from a less mature to an increasing sophistication over time:

- $\quad$ Stage 1: There is no clear direction for the organization's e-business initiatives;

- Stage 2: E-business initiatives are increasingly considered to be an important component of the organization business. However, there is no proper planning and a lack of direction for IS/IT development and implementation;

- Stage 3: E-business initiatives are considered an important component of the organization's business. There is a clear direction for the development of e-business initiatives within the organization. However, e-business development is still very much focused on technology-centric perspective and not influenced by business needs;

- Stage 4: E-business adoption and development is becoming more business-focused. There is a move towards integration and greater coordination between the components of e-business (e.g. IS/IT and the Internet) and the organization's business processes.

- Stage 5: Integration between traditional business processes and activities and e-business processes and activities creates seamless communication and flow of processes within an organization. E-business initiatives aim to provide strategic benefits by building strategic systems;

- Stage 6: E-business is deeply embedded throughout every aspect of the organization. There is a strong integration between the components of e-business and business processes within the organization as well as with those of its suppliers and business partners. E-business initiatives are aimed at creating and maintaining the organization strategic advantage.

\section{Results}

\section{Demographics}

The sample is characterized by values on several variables that are displayed in table 1. The respondents self-reported all the demographic values that are reported.

Within the sample, the major percentage of respondents are directors (44\%), followed by respondents who answered that they have another function than those listed $(27 \%)$ and by respondents who are executives (15\%). Only $8 \%$ are administrators and $6 \%$ are general directors of the organization. The respondents, who answered "Other" as a function, are the majority responsible for the department of IT/IS within the organization.Concerning their education, $17 \%$ of the respondents answered that they have secondary education, $27 \%$ have a post-graduate and $56 \%$ of respondents have a bachelor degree. The major percentage of organizations have between 50 to 249 employees (63\%), followed by organizations that have between 10 to 49 employees (23\%) and the organizations with more than 500 employees (10\%). Only a small percentage of organizations have between 250 and 499 employees (4\%). It appears that most organizations (92\%) have a website and only a small proportion (8\%) still have no site. 
Table 1. Demographic values

\begin{tabular}{|c|c|c|}
\hline & \% of Respondents & $\mathbf{N}^{0}$ of Respondents \\
\hline \multicolumn{3}{|c|}{ Function } \\
\hline Administrator & $8 \%$ & 4 \\
\hline General Director & $6 \%$ & 3 \\
\hline Director & $44 \%$ & 23 \\
\hline Executive & $15 \%$ & 8 \\
\hline Other & $27 \%$ & 14 \\
\hline \multicolumn{3}{|c|}{ Education Level } \\
\hline Secondary School & $17 \%$ & 9 \\
\hline Higher Education & $56 \%$ & 29 \\
\hline Post-Graduation & $27 \%$ & 14 \\
\hline \multicolumn{3}{|c|}{ Number of employees } \\
\hline 10 to 49 & $23,1 \%$ & 12 \\
\hline 50 to 249 & $63,5 \%$ & 33 \\
\hline 250 to 499 & $3,8 \%$ & 2 \\
\hline More than 500 & $9,6 \%$ & 5 \\
\hline \multicolumn{3}{|c|}{ Web Site } \\
\hline No & $8 \%$ & 4 \\
\hline Yes & $92 \%$ & 48 \\
\hline
\end{tabular}

Figure 1 shows the evolution of the maturity of the final sample between 2005 and 2008 .

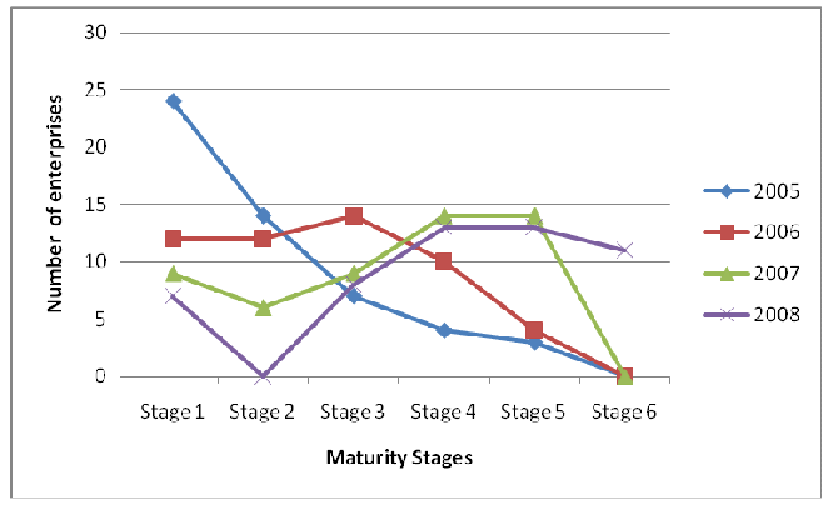

Fig1. Evolution of the e-business maturity (2005 - 2008)

Relationship between IT and e-business maturity

Based on the results above, we can conclude that the digital economy is a reality in Portugal, not just for large companies as it is mentioned in Morais, Pires and Gonçalves (2009), but also for
Portuguese SMEs, with a clear evolution in the maturity of the NE.Furthermore, the questionnaire focused a number of technologies: Enterprise Resource Planning (ERP), Customer Relationship Management (CRM), Supply Chain Management (SCM), Data warehouse, Business Intelligence (BI), Electronic Data Interchange (EDI), Business-to-Business (B2B), Business-to- 
Consumer (B2C), Business-to-Government (B2G), Workflow, Groupware and Knowledge Management (KM). In order to explore the relationship between technology and the maturity, we used the Spearman correlation test. The maturity is an ordinal variable with values from one to six, corresponding to stage one to stage six respectively, and the technologies are ordinal variables with values from one to four, corresponding to Implemented, In Development, Planned and unplanned respectively. The result of the test states in table 2 .

Table 2. Correlation between the technologies and the maturity in 2008

\begin{tabular}{|c|c|c|}
\hline & & Maturity in 2008 \\
\hline \multirow{3}{*}{ ERP } & Correlation Coeficient &,- 106 \\
\hline & Sig. (2-tailed) & 455 \\
\hline & $\mathrm{N}$ & 52 \\
\hline \multirow{3}{*}{ CRM } & Correlation Coeficient &,$- 329 *$ \\
\hline & Sig. (2-tailed) &, 017 \\
\hline & $\mathrm{N}$ & 52 \\
\hline \multirow{3}{*}{ SCM } & Correlation Coeficient &,- 174 \\
\hline & Sig. (2-tailed) & ,217 \\
\hline & $\mathrm{N}$ & 52 \\
\hline \multirow{3}{*}{ DW } & Correlation Coeficient &,- 221 \\
\hline & Sig. (2-tailed) &, 115 \\
\hline & $\mathrm{N}$ & 52 \\
\hline \multirow{3}{*}{ BI } & Correlation Coeficient &,$- 318^{*}$ \\
\hline & Sig. (2-tailed) &, 022 \\
\hline & $\mathrm{N}$ & 52 \\
\hline \multirow{3}{*}{ EDI } & Correlation Coeficient &,$- 393 * *$ \\
\hline & Sig. (2-tailed) & ,004 \\
\hline & $\mathrm{N}$ & 52 \\
\hline \multirow{3}{*}{ B2B } & Correlation Coeficient &,$- 574 * *$ \\
\hline & Sig. (2-tailed) &, 000 \\
\hline & $\mathrm{N}$ & 52 \\
\hline \multirow{3}{*}{ B2C } & Correlation Coeficient &,- 256 \\
\hline & Sig. (2-tailed) & ,067 \\
\hline & $\mathrm{N}$ & 52 \\
\hline \multirow{3}{*}{ B2G } & Correlation Coeficient &,$- 278^{*}$ \\
\hline & Sig. (2-tailed) &, 046 \\
\hline & $\mathrm{N}$ & 52 \\
\hline \multirow{3}{*}{ Workflow } & Correlation Coeficient &,$- 332 *$ \\
\hline & Sig. (2-tailed) &, 016 \\
\hline & $\mathrm{N}$ & 52 \\
\hline \multirow{3}{*}{ Groupware } & Correlation Coeficient &,- 172 \\
\hline & Sig. (2-tailed) & ,222 \\
\hline & $\mathrm{N}$ & 52 \\
\hline \multirow{3}{*}{ KM } & Correlation Coeficient &,- 239 \\
\hline & Sig. (2-tailed) &, 088 \\
\hline & $\mathrm{N}$ & 52 \\
\hline
\end{tabular}

The table shows that the correlation of the maturity in 2008 with the technologies Workflow, B2G, CRM and BI, is significant at $5 \%$, and the correlation of maturity with the EDI and B2B technologies is significant at $1 \%$. This means, that the higher the level

of maturity, the greater the probability that the technologies will be implemented, and the lower the stage of maturity, the greater the probability that these technologies do not exist in the organization. This result indicates that if the organization is in a 
more advanced stage of maturity, the greater the probability of implementing the following technologies: Workflow, B2G, CRM, BI, EDI and B2B. Similarly, if the organization is in a lower stage of maturity, the probability increases that the technologies do not exist in the organization.

\section{Conclusions}

With an increasingly global world and a higher degree of competitiveness, organizations that want to survive the challenges of the market, must be able to adapt themselves quickly to fast changing environments. This leads to the need for systems that can adapt at the same pace and it is important that organizations recognize the impact that e-business strategies and plans may have, and that this impact will also influence their customers and therefore the success of the organization. This study intended to identify the evolution of the e-business maturity of 500 Portuguese SMEs since 2005 until the year 2008 and explore the relationship between the e-business maturity and the technology. We can verify that most organizations have a Web site and we can also verify that the organizations are sensitive to the issue because of the evolution of the maturity of NE identified since the year 2005 until 2008. Organizations understand that ebusiness may be a competitive advantage and in order to manage the business and gain improved performance in the market it's not merely an option but a matter of survival. Stone, Good and Baker-Eveleth (1997) defend that understanding which benefits a strategic tool can bring to an organization is a critical issue, but understanding which benefits a strategic tool can bring to the maturity of an organization is even more critical. It's not possible to determine the benefits, but through our study, we can conclude that there is some correlation between some of the technology and e-business maturity of an organization.

\section{References}

Alreck, L., and Settle, B. (1985) The survey research handbook, McGraw-Hill Higher Education.

Alves, J. (2009) "Gestão de projectos: como se preparar adequadamente" [Online], [Retrieved 2009], http://imasters.uol.com.br/artigo/ 9781/gerencia/gestao de projetos como se preparar adequadament e/

Barnett, V. (1991) Sample survey: Principles and methods, Hodder Arnold.

Bhabuta, L. (1988) "Sustainig Productivity and Competitiveness by Marshalling IT" Proceedings of the IFIP TC8 Open Conference.

Chan, C., and Swatman, P. (2004) "B2B ECommerce Stages of Growth: the strategic imperatives" Proceedings of the 37th Annual Hawaii International Conference of System Sciences.

Earl, M. J. (1983) "Emerging trends in managing new information technologies" in The Management Implications of New Information Technology. London: Oxford Centre for Management Studies.

Earl, M. J. (1989) Management Strategies for Information Technology.

Earl, M. J. (2000) "Evolving the E-Business", Business Strategy Review (11).

Exame. (2008) "Listagem das 1000 melhores PME portuguesas" [Online], [Retrieved November 6, 2008],

http://exame.edimpresa.viatecla.p t/especiaisdetalhe.aspx?channelid =4E23AD7D-3F76-46F4-8E5D-

4FD7B4BB829C\&contentid=DC1E 8770-7256-4833-92CF-

3B2C5A6B1221 
Galliers, R. D., and Sutherland, A. R. (1994) "Informations Systems Management and Strategy Formulations: Applying and Extending the 'Stages of Growth' Concept", in Strategic Information Management: Challenges and Strategies in Managing Information Systems: Butterworth-Heinemann Ltd Oxford.

Gibson, C. F., and L.R., N. (1974) "Managing the Four Stages of EDP Growth", Harvard Business Review, pp. 7688.

Gonçalves, R. (2005) "Modelo Explicativo das Iniciativas de Comércio Electrónico",University of Trás-osMontes and Alto Douro, Vila Real.

Grant (1999) "E-Commerce for Small Businesses", Proceedings of the 2nd International Conference, Manchester, England.

Hirschheim, R., Earl, M., Feeny, D., and Lockett, M. (1988) "An Exploration into the Management of the Information Systems Function: Key Issues and an Evolutionary Model" Proceedings of the IFIP TC8 Open Conference.

IBM (1997) [Retrieved 1997] www.ibm.com

KPMG (1997) Electronic Commerce Research Report, London, United Kingdomo.

McKay, J., Prananto A., and Marshall P. (2000) "E-business Maturity: The SOG-e Model" Proceedings of the 11th Australasian Conference on Information Systems (ACIS).

Morais, E., Pires, J., and Gonçalves, R. (2008) "Constrangimentos associados à evolução do Negócio Electrónico em Portugal" 8a Conferência da Associação Portuguesa de Sistemas de Informação.
Morais, E., Pires, J., and Gonçalves, R. (2009) "E-Business maturity and information technology" International Conference on Web Information Systems and Technologies (WEBIST), Lisboa.

Nolan, R. L. (1973) "Managing the Computer Resource: A Stage Hypothesis," Communications of the ACM (16), pp. 399-405.

Plessis, M., and Boon, J. (2004) "Knowledge management in e-Business and customer relationship management: South African case study findings," International Journal of Information Management, pp. 73-86.

Prananto, A., McKay, J., and Marshall, P. (2003) "A Study of the Progression of E-Business Maturity in Australian SMEs: Some Evidence of the Applicability of the Stages of Growth for E-Business Model" PACIS 2003 Proceedings.

Prananto, A., McKay, J., and Marshall, P. (2004) "Exploring the perceptions of inhibitors and drivers of $\mathrm{E}$ Business progression amongst SMEs at different stages of EBusiness maturity" Conference proceedings of the European Conference on Information Systems 2004, Turku, Finland.

Prananto A., McKay J., and Marshall P. (2001) "Frameworks to Support EBusiness Strategy" Global CoOperation in the New Millennium: The 9th European Conference on Information Systems.

Rao, S., Metts, G., and Monge, A. (2003) "Electronic Commerce Development in Small and Medium Sized Enterprises: A stage Model and its Implications," Business Process Management Journal (9:1). 
Rayport, J., and Jaworsky, B. (2002) Introduction to E-Commerce: McGraw-Hill.

Stone, R., Good, D., and Baker-Eveleth, L. (2007) "The impact of information technology on individual and firm marketing performance," Behaviour and Information Technology (26:6), pp.465-482. 